\title{
Prevalence and family biosocial predictors of abdominal obesity among adult Nigerian Africans in a resource constrained setting of a rural hospital in Eastern Nigeria
}

\author{
Gabriel Uche Pascal Iloh ${ }^{1, ~ *, ~ A g w u ~ N k w a ~ A m a d i ~}{ }^{2}$, Augustine Obiora Ikwudinma ${ }^{3}$, \\ Patrick Uchenna Njoku ${ }^{1}$ \\ ${ }^{1}$ Department of Family Medicine, Federal Medical Centre, Umuahia, Abia state, Nigeria \\ ${ }^{2}$ Department of Public Health Technology, Federal University of Technology, Owerri, Imo state, Nigeria \\ ${ }^{3}$ Department of Family Medicine, Federal Teaching Hospital Abakiliki, Nigeria
}

\section{Email address:}

ilohgup2009@yahoo.com (G. U. P. Iloh)

To cite this article:

Gabriel Uche Pascal Iloh, Agwu Nkwa Amadi, Augustine Obiora Ikwudinma, Patrick Uchenna Njoku. Prevalence and Family Biosocial Predictors of Abdominal Obesity among Adult Nigerian Africans in a Resource Constrained Setting of a Rural Hospital in Eastern Nigeria. European Journal of Preventive Medicine. Vol. 1, No. 3, 2013, pp. 70-78. doi: 10.11648/j.ejpm.20130103.14

\begin{abstract}
Background: The variability of abdominal obesity within and across families is influenced by several factors. However, the relevance of family biosocial factors in the variability of abdominal obesity is an important health care challenge that is often neglected especially in this era of personalized medicine. Aim: This study was designed to determine the prevalence and family biosocial predictors of abdominal obesity among adult Nigerian Africans in a resource constrained setting of a rural hospital in Eastern Nigeria. Materials and Methods: A cross sectional analytic study carried out on 3012 adult patients aged 18-91 years who were screened for abdominal obesity using the Third Report of National Cholesterol Education Panel (NCEP) in adult (ATP III) criterion and 350 patients who had waist circumference (WC) $\geq 102 \mathrm{~cm}$ and $\geq 88 \mathrm{~cm}$ for men and women respectively and met the inclusion criteria were age and sex matched with 350 non-obese, non-hypertensive and non-diabetic control. Family bio-social variables were obtained using a pretested, structured and interviewer-administered questionnaire. Hypertension and diabetes mellitus were defined using Joint National Committee 7 Report on Prevention, Detection, Evaluation and Treatment of High Blood Pressure and American Diabetic Association criteria respectively. Results: .The prevalence of abdominal obesity was $11.6 \%$. The family biosocial variables significantly associated with abdominal obesity were family history of obesity $(\mathrm{p}=0.036)$ and family inadequate dietary fruits consumption $(\mathrm{p}=0.042)$. The most significant predictor of abdominal obesity was family history of obesity $(\mathrm{OR}=2.60, \mathrm{CI}=0.95-13.01, \mathrm{p}=0.022)$. The patient with family history of obesity was two and half times more likely to be obese than those without family history of obesity. Conclusion: Abdominal obesity is associated with family history of obesity and inadequate dietary fruits consumption. The interventional control programs for abdominal obesity should consider these risk factors alongside the complex of other cardiovascular risk factors.
\end{abstract}

Keywords: Abdominal Obesity, Family Biosocial Predictors, Hospital, Rural Nigeria

\section{Introduction}

Abdominal obesity is socially acceptable among Nigerian Africans and therefore is not usually recognized as a health risk.[1-3] It is a medical problem in which excess fat has accumulated in the abdomen to the extent that it may have an adverse effect on health and/or increase medical problems.[1,2] It was once thought the health problem of affluent advanced countries but now exists in Nigeria in varying prevalence ranges[1-3,5] and has been described as a time bomb for the future explosion in the frequency of cardiovascular disease and metabolic syndrome.[1,4,5] Globally, in the past, abdominal obesity was viewed as a sign of wealth and wellness.[1,3,6] However, in the present, public perceptions of healthy body shape and weight have changed significantly since the beginning of the epidemic of obesity, metabolic syndrome and cardiovascular diseases. [6-8] Normal adiposity of the 
abdomen (flat abdomen) is viewed as the ideal abdominal adiposity in western societies [6,7] in contrast to the perception in traditional Nigerian societies where protruding abdomen (abdominal obesity) is culturally perceived as a symbol of good health and wealth.[1,3,5]

The clinical criteria for defining obesity have been variously described including anthropometric measurement of body mass index, $[9,10,11]$ waist circumference (WC), [1,5] waist hip ratio, [2] neck circumference [12] among others and imaging techniques such as computed tomography scan and magnetic resonance imaging.[1,2] Although, the imaging methods are the gold standard for assessing abdominal adiposity, they are expensive for large scale epidemiological studies.[1,2] Waist circumference is therefore one of the most popular measures of abdominal adiposity and the simplest anthropometric index of abdominal obesity. [1,2] The validity of WC as a measure of abdominal obesity is further supported by its association with obesity-related risk factors $[1,7,13]$ and a crucial correlate of metabolic syndrome.[14] The waist circumference therefore provides an easy method of describing pattern of abdominal obesity even if the body mass index is about right.[5,15] The metabolic and structural changes in obese individuals are most often seen in abdominal obesity $[1,15,16]$ and have consistently been related to increased risk of coronary heart disease in men[17] and women.[18] Obesity is defined using waist circumference (WC) criterion as an excess of adipose tissues resulting in waist circumference $\geq 102 \mathrm{~cm}$ ( 40 inches) and $\geq 88 \mathrm{~cm}$ (35 inches) for men and women respectively.[19] Similarly, abdominal overweight refers to the waist circumference between $94-101 \mathrm{~cm}$ and $80-87 \mathrm{~cm}$ for men and women respectively.[19]

The prevalence of obesity as defined by waist circumference in the developing nations such as Nigeria is changing.[1,2,4,5] Ongoing nutritional, socio-economic and demographic, family-related lifestyle and epidemiologic changes in Nigeria have contributed to the burden of abdominal obesity.[1,5,20,21] The prevalence of abdominal obesity has been reported within and across populations in Nigeria[1,2,5,22] and other parts of the world such as United States of America,[23], South Korea [24] and Cotonou, Benin Republic.[25] In Nigerian Africans a prevalence of $50.8 \%$ was reported among geriatric hypertensives in Amurie Omanze, Imo state[1]; $21.7 \%$ was reported in selected rural and urban communities of Abia state, Nigeria;[5] 31.7\% was reported in Okirika, Rivers state, Nigeria;[2] 16.9\% was reported in Port Harcourt, Nigeria, [2] and 33.8\% was reported in Ogbomoso, Western, Nigeria.[22]

The development of any medical conditions such as abdominal obesity is influenced by predisposing, promotional and enabling risk factors and these factors interact to contribute to the morbid clinical picture.[1,2] The predisposition factors include family-related bio-social characteristics such as type of family, family structure, family size, type of marriage, family diets, family physical activities, and family history of cardio-metabolic disorders among others.[1,9,10,11] These family biosocial variables have been documented to influence disease morbidity profiles in Nigerian families.[11,26,27] The promotional factors include health promotional and wellness technologies and programs. The enabling factors include quality of care, policy direction on obesity control services and existence of public health network for obesity. Studies have also shown that family environment is instrumental in the development of obesity and obesity tend to cluster in families with variable distribution and penetrance.[11,21,28,29,30] Although, the mechanisms involved in the development of obesity have been elucidated but there is now evidence for strong genetic influence and most human obesity develops from the interactions of multiple genes, environmental and behavioural factors.[30,31]

The variability of abdominal obesity within and across Nigerian populations have been reported in different parts of the country.[1,2,5,22] However, there is absence of data on family biosocial factors associated with abdominal obesity in Nigeria. Failure to recognize abdominal obesity as a family health condition has serious implications for control interventions. Identification of these family biosocial associations and targeting them for primary prevention will improve the health status of Nigerians in the study area as regards abdominal obesity and its medical correlates. It is against this background that this study was designed to determine the prevalence and family biosocial predictors of abdominal obesity among adult Nigerian Africans in a resource constrained setting of a rural hospital in Eastern Nigeria.

\section{Materials and Methods}

\subsection{Ethical Consideration}

Ethical certificate was obtained from the Ethics Committee of the hospital. Informed consent was also obtained from respondents included in the study.

\subsection{Study Design}

This was a hospital-based cross sectional analytic study carried out between June 2008 and June 2011. A total of 3012 adult patients aged 18-91 years were screened for abdominal obesity using the Third Report of National Cholesterol Education Panel(NCEP) in adult (ATP III) criterion and 350 patients who had $\mathrm{WC} \geq 102 \mathrm{~cm}$ and $\geq 88 \mathrm{~cm}$ for men and women respectively were age and sex matched with 350 nonobese, non-hypertensive and non-diabetic control.

\subsection{Study Setting}

Amurie-Omanze is a rural community in Imo State, South-East Nigeria. Imo State is endowed with abundant mineral and agricultural resources with supply of professional, skilled, semi-skilled and unskilled manpower. Economic and social activities are low compared to 
industrial and commercial cities such as Onitsha, Port Harcourt and Lagos in Nigeria.

St Vincent De Paul Hospital is a rural General Hospital in Imo state, South-east Nigeria and renders twenty four hours service daily including public holidays to the community.

\subsection{Study Population}

The study population was made up of 350 adult patients who had abdominal obesity and met the inclusion criteria. This category of patients constituted the cases. The control population was also selected from outpatient clinic of the hospital and was made up of 350 non-abdominally obese, non-hypertensive and non-diabetic patients.

The control group was matched for age and sex with the cases. The matching for the age was based on age group matching as in the case category. The cases and control were studied simultaneously during the study period

\subsection{Inclusion and Exclusion Criteria}

The inclusion criteria were abdominally obese patients aged $\geq 18$ years who gave informed consent for the study. The exclusion criteria were critically ill patients, pregnant women, women in pueperium, patients with demonstrable ascites and intra-abdominal masses determined by history and physical examination. The five patients that were used in pre-testing the questionnaire who may be influenced by their previous interaction with the content of the questionnaire were also excluded.

\subsection{Sample Size Determination}

The sample size $(N)$ was calculated using the formula for comparative study [32] $\mathrm{N}=[(\mathrm{Z} \alpha+\mathrm{Z} \beta) \times 2 \mathrm{pq}] / \mathrm{d}^{2}$ Where $\mathrm{N}$ $=$ Desired sample size, $\mathrm{Z}=$ The standard normal deviate set at 1.96 which correspond to $95 \%$ confidence level. $\mathrm{P}=$ the prevalence of abdominal obesity of $33.8 \%$ from a previous study in Ogbomoso, Nigeria.[22] $\mathrm{q}=1.0-\mathrm{p}$, and $\mathrm{d}=$ degree of precision desired set at 0.05 The level of significance was set at $5 \%(\alpha=0.05)$ while the power of the study $(1-\beta)$ was set at $80 \% . \quad \mathrm{N}=[(1.96 \times 0.05+1.96 \times 0.2) \quad \mathrm{x}$ $2 \times 0.33 \times 0.67] / 0.05^{2}=86$. Therefore, $\mathrm{N}=86$.

The calculated minimum sample size was 86 . However, to improve the precision of the study, the estimated sample size $=\mathrm{Ns}$ was determined considering an anticipated response rate of $90 \%(0.9)$. The estimated sample size (Ns) was determined by dividing the original calculated sample size $(\mathrm{N})$ by the anticipated response rate [33] as follows, $\mathrm{Ns}=\mathrm{N} / 0.9$, where $\mathrm{N}=$ Minimum calculated sample size, $\mathrm{Ns}=$ Selected sample size, anticipated response rate $=0.9$. Thus, the estimated sample size $=86 / 0.9=95$. However, a sample size of 350 cases and 350 control groups were used for representativeness of the study population.

\subsection{Sampling Technique}

Sample selection was done consecutively based on the inclusion criteria for the abdominally obese patients. The control group was selected simultaneously based on those that met the matching criteria with the cases.

\subsection{Diagnostic Procedures}

The waist circumference was measured using flexible non-stretchable tape.[1,33] The subject stood erect with arms at the side and feet together. The researcher faced the subject. The iliac crest and lower rib cage were first identified by palpation. The waist circumference was taken as the midpoint between the lower border of lower rib cage and iliac crest in a horizontal plane parallel to the floor.[1]

The blood pressure was measured using auscultatory method with standard mercury in glass Accuson sphygmomanometer.[1,9-11,28,33] The blood glucose was determined after an overnight fast between 8.00 hours to 10.00 hours using venous plasma by glucose oxidase method.[1,9-11,28,33] A repeat fasting plasma glucose was done for those who had abnormal fasting plasma glucose test result on the next scheduled clinic visit.

\subsection{Diagnostic Criteria}

Abdominal overweight was defined as waist circumference from $94 \mathrm{~cm}$ to $101 \mathrm{~cm}$ for men and $80 \mathrm{~cm}$ to $87 \mathrm{~cm}$ for women while abdominal obesity was defined as waist circumference $\geq 102 \mathrm{~cm}$ and $\geq 88 \mathrm{~cm}$ for men and women respectively.[19]

Blood pressure readings were based on the Joint National Committee 7 Report on Prevention, Detection, Evaluation and Treatment of High Blood Pressure classification and guidelines.[1,9-11,28,33,34] Hypertension was defined as systolic and/or diastolic blood pressure $\geq 140 / 90 \mathrm{mmHg}$ and/or documented use of antihypertensive medications in a previously diagnosed person with hypertension.[34]

Diabetes mellitus was defined based fasting venous plasma glucose of $\geq 126 \mathrm{mg} / \mathrm{dL}$ which was confirmed by a repeat test on second clinic visit or current use of antidiabetic medications. [35]

\subsection{Methods}

Data collection instrument had two sections: The basic demographic factors and family biosocial variables. The questionnaire instrument was adapted from the generic WHO-STEPS instrument approach to surveillance of chronic non-communicable diseases risk factors [36] and was modified to suit Nigeria environment through robust review of relevant literature.[1-5,9-11,26-28,37] The basic demographic variables of age, sex, occupation, education and social class and family biosocial factors like type of household, type of marriage, family structure, family size and family histories of primary cardiovascular risk factors such as obesity, hypertension and diabetes mellitus, family dietary fruits and vegetables consumption during meal times and type of oil use in household meal preparations..

The family history of obesity, hypertension and diabetes mellitus was coded as yes or no for the presence or absence of obesity, hypertension and diabetes mellitus in any of the 
first, second or third degree generation family members respectively.

The family behavioural risk factor of dietary fruits and vegetables consumption were evaluated by asking how many days in the previous 7 days do the family eat fruits and vegetables. The dietary responses were graded into: never ( 0 serving/week), rarely $(<3$ servings/week) and oftentimes ( $\geq 3$ servings/week). Those who have $\geq 3$ servings/week have adequate dietary fruits intake while those who had 0 serving/week and $<3$ servings/week have inadequate dietary fruits and vegetables consumption respectively. The question on family dietary use of oils was got by inquiring in the previous 7 days the type of oil used in household meal preparations. The information on family behavioural measurements was based on previous 7 days dietary recall method. This method was expected to give required information on family dietary assessment based on the feasibility and the Nigerian rural practice population setting. The researchers explained briefly the concept of the study and made vigorous effort to maximize positive response in order to minimize the potential for information bias especially response acquiescence and social desirability response.

The pre-testing of the questionnaire was done internally at the hospital using five obese and five non-obese patients from the outpatient clinic. The pre-testing of the questionnaire lasted for two days. The respondents for the pre-testing of the questionnaire were selected haphazardly from the clinic. The pretesting was done to find out how the questionnaire would interact with the respondents and ensured that there were no ambiguities. However, no change was necessary after the pre-test as the questions were interpreted with the same meaning as intended.

The questionnaire instrument was intervieweradministered. Language used was English Language. However, local languages were used to explain verbally to the patients who could not understand the medical language in the questionnaire. The questionnaire was administered once to each eligible respondent.

\subsection{Operational Definitions}

The researchers defined adult patients as those age 18 years and above.[9-11] Biosocial risk factors of abdominal obesity refer to antecedent condition(s) whose presence is(are) positively associated with an increased probability that abdominal obesity will develop later. The biosocial risk factors studied included the traditional non-modifiable factors of age, sex, family history of obesity, hypertension and diabetes mellitus; modifiable behavioural risk factors of dietary fruits, vegetables and household cooking oils. Family history of obesity, hypertension or diabetes refers to previous information on obesity, hypertension or diabetes mellitus in any of the first, second or third degree generation family members who were dead or alive made by a health professional.[11] Family refers to two parents and their children or single parent family made of either parent and their children. Household family in Nigerian family demographic geography refers to a number of persons eating from the same pot.

\subsection{Statistics}

The results generated were analyzed using software Statistical Package for Social Sciences (SPSS) version 13.0, Microsoft coperation, Inc. Chicago, IL, USA. Categorical variables were described by frequencies and percentages. Bivariate analysis involving Chi-square test was used to test for the significance of associations between categorical variables. Furthermore, to identify family biosocial variables independently associated with abdominal obesity, simple logistic regression analysis was performed at $95 \%$ confidence limit. The level of significance was set at $\mathrm{p}<0.05$.

\section{Results}

Of the 3012 adult patients screened for abdominal obesity, three hundred and fifty were abdominally obese giving a prevalence of $11.6 \%$. One thousand, one hundred and seventy four $(39.0 \%)$ had pre-abdominal obesity (overweight abdominal adiposity) while one thousand, four hundred and eighty-eight (49.4\%) had normal abdominal adiposity.[Table 1]

The age of the abdominally obese patients ranged from 18 years to 91 years with mean age of $48 \pm 10.1$ years whilst the age of the control group ranged from 18 years to 88 years with mean age of $47 \pm 12.5$ years. There were one hundred and fifty four $(44.0 \%)$ males and one hundred and ninety six $(56.0 \%)$ females with male to female ratio of $1: 1.3$. Other socio-demographic profiles of the study population are shown in Table 2 .

Bivariate analysis of predictor family biosocial variables as related to abdominal obesity showed that family history of obesity $\left(\mathrm{x}^{2}=13.09, \mathrm{P}=0.036\right)$ and family inadequate dietary fruits consumption $\left(\mathrm{x}^{2}=8.06, \quad \mathrm{P}=0.042\right)$ were statistically significant while other variables were not statistically significant.[Table 3]

On logistic regression of the statistically significant variables family history of obesity remained statistically significant.[Table 4] A significantly higher proportion of the abdominally obese patients had family history of obesity compared to the non obese control.(OR=2.60, $\mathrm{CI}=0.95-13.01$, P-value $=0.022)$ The abdominally obese patients were two and half times more likely to have family history of obesity compared to the non abdominally obese control.

Table 1. Distribution of the screened patients based on abdominal adiposity

\begin{tabular}{ll}
\hline Parameter & Number (\%) \\
\hline $\begin{array}{l}\text { Normal abdominal adiposity } \\
\text { Pre-abdominal obesity (overweight abdominal }\end{array}$ & $1488(49.4)$ \\
adiposity) & $1174(39.0)$ \\
Abdominal obesity & $350(11.6)$ \\
Total & $3012(100.0)$ \\
\hline
\end{tabular}


Table 2. Basic socio-demographic variables of the study population

\begin{tabular}{|c|c|c|}
\hline Variables & 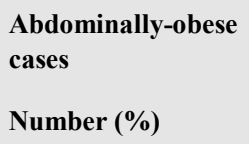 & $\begin{array}{l}\text { Abdominally non- } \\
\text { obese control } \\
\text { Number }(\%)\end{array}$ \\
\hline \multicolumn{3}{|l|}{ Age(years) } \\
\hline $18-39$ & $36(10.3)$ & $36(10.3)$ \\
\hline $40-60$ & $183(52.3)$ & $183(52.3)$ \\
\hline$>60$ & $131(37.4)$ & $131(37.4)$ \\
\hline Total & $350(100.0)$ & $350(100.0)$ \\
\hline \multicolumn{3}{|l|}{ Sex } \\
\hline Male & $154(44.0)$ & $154(44.0)$ \\
\hline Female & $196(56.0)$ & $196(56.0)$ \\
\hline Total & $350(100.0)$ & $350(100.0)$ \\
\hline \multicolumn{3}{|l|}{ Marital status } \\
\hline Single & $15(4.3)$ & $34(9.7)$ \\
\hline Married & $233(66.6)$ & $225(64.3)$ \\
\hline Widowed & $94(26.8)$ & $86(24.6)$ \\
\hline Separated/Divorced & $8(2.3)$ & $5(1.4)$ \\
\hline Total & $350(100.0)$ & $350(100.0)$ \\
\hline \multicolumn{3}{|l|}{ Education } \\
\hline Primary and less & $80(22.9)$ & $44(12.6)$ \\
\hline Secondary and more & $270(77.1)$ & $306(87.4)$ \\
\hline Total & $350(100.0)$ & $350(100.0)$ \\
\hline \multicolumn{3}{|l|}{ Occupation } \\
\hline Unemployed & $36(10.3)$ & $18(5.1)$ \\
\hline Student/Apprentice & $12(3.4)$ & $10(2.9)$ \\
\hline Public/civil servants & $39(11.1)$ & $61(17.4)$ \\
\hline Farming & $107(30.6)$ & $94(26.9)$ \\
\hline Trading & $46(13.1)$ & $59(16.9)$ \\
\hline Artisans & $48(13.7)$ & $36(10.3)$ \\
\hline Driving & $8(2.3)$ & $5(1.4)$ \\
\hline Clergy & 11(3.1) & $16(4.6)$ \\
\hline Retirees & $43(12.4)$ & $51(14.5)$ \\
\hline Total & $350(100.0)$ & $350(100.0)$ \\
\hline \multicolumn{3}{|l|}{ Social class } \\
\hline Lower class & $285(81.4)$ & $213(60.9)$ \\
\hline Middle class & $47(13.4)$ & $94(26.9)$ \\
\hline Upper class & $18(5.2)$ & $43(12.2)$ \\
\hline Total & $350(100.0)$ & $350(100.0)$ \\
\hline
\end{tabular}

Table 3. Family biosocial variables as related to abdominal obesity among the study population

\begin{tabular}{|c|c|c|c|c|}
\hline Variables & 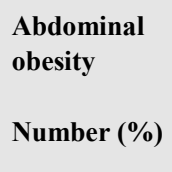 & $\begin{array}{l}\text { Non-obese } \\
\text { control } \\
\text { Number } \\
(\%)\end{array}$ & $\mathbf{x}^{2}$ & P-value \\
\hline \multicolumn{5}{|c|}{ Type of marital union } \\
\hline Monogamous & $329(94.0)$ & $337(96.3)$ & & \\
\hline Polygamous & $21(6.0)$ & $13(3.7)$ & & \\
\hline Total & $350(100.0)$ & $350(100.0)$ & 3.17 & $0.190 * *$ \\
\hline \multicolumn{5}{|c|}{ Type of family structure(household) } \\
\hline $\begin{array}{l}\text { Nuclear household } \\
\text { family }\end{array}$ & $320(91.4)$ & $337(96.3)$ & & \\
\hline $\begin{array}{l}\text { Extended } \\
\text { household family }\end{array}$ & $30(8.6)$ & $13(3.7)$ & & \\
\hline Total & $350(100.0)$ & $350(100.0)$ & 5.05 & $0.272 * *$ \\
\hline \multicolumn{5}{|l|}{ Type of parenthood } \\
\hline Single parenthood & $102(29.1)$ & $91(26.0)$ & & \\
\hline Both parenthood & $248(70.9)$ & $259(74.0)$ & & \\
\hline Total & $350(100.0)$ & $350(100.0)$ & 2.98 & $0.106^{* *}$ \\
\hline \multicolumn{5}{|l|}{ Family size } \\
\hline $1-4$ & $84(24.0)$ & $111(31.7)$ & & \\
\hline$>4$ & $266(76.0)$ & $239(68.3)$ & & \\
\hline Total & $350(100.0)$ & $350(100.0)$ & 7.09 & $0.606 * *$ \\
\hline \multicolumn{5}{|c|}{ Family history of hypertension } \\
\hline Yes & $233(66.6)$ & $152(43.4)$ & & \\
\hline No & $117(33.4)$ & $198(56.6)$ & & \\
\hline Total & $350(100.0)$ & $350(100.0)$ & 3.14 & $0.170 * *$ \\
\hline \multicolumn{5}{|c|}{ Family history of diabetes mellitus } \\
\hline Yes & $66(18.9)$ & $28(8.0)$ & & \\
\hline No & $284(81.1)$ & $322(92.0)$ & & \\
\hline Total & $350(100.0)$ & $350(100.0)$ & 11.74 & $0.068 * *$ \\
\hline \multicolumn{5}{|c|}{ Family history of obesity } \\
\hline Yes & $318(90.9)$ & $105(30.0)$ & & \\
\hline No & $32(9.1)$ & $245(70.0)$ & & \\
\hline Total & $350(100.0)$ & $350(100,0)$ & 13.09 & $0.036^{*}$ \\
\hline \multicolumn{5}{|c|}{ Family dietary fruits consumption } \\
\hline Adequate & $66(18.9)$ & $144(41.1)$ & & \\
\hline Inadequate & $284(81.1)$ & 194(58.9) & & \\
\hline Total & $350(100.0)$ & $350(100.0)$ & 8.06 & $0.042 *$ \\
\hline \multicolumn{5}{|c|}{ Family dietary vegetables consumption } \\
\hline Adequate & $95(27.1)$ & $106(30.3)$ & & \\
\hline Inadequate & $255(72.9)$ & $244(69.7)$ & & \\
\hline Total & $350(100.0)$ & $350(100.0)$ & 9.14 & $0.055^{* *}$ \\
\hline \multicolumn{5}{|c|}{ Family dietary oils consumption } \\
\hline Saturated & 283(80.9) & $239(68.3)$ & & \\
\hline Unsaturated & $67(19.1)$ & $111(31.7)$ & & \\
\hline Total & $350(100.0)$ & $350(100.0)$ & 3.75 & $0.264 * *$ \\
\hline
\end{tabular}

Remark: *Significant, **Non-significant 
Table 4. Predictors of abdominal obesity among the abdominally obese patients

\begin{tabular}{lccc}
\hline Variables & $\begin{array}{l}\text { Odds } \\
\text { ratio }\end{array}$ & $\begin{array}{l}\text { Confidence } \\
\text { interval (95\%) }\end{array}$ & P-value \\
\hline \multicolumn{2}{l}{ Family history of obesity } & \\
No & 1.0 & $0.95-13.01$ & 0.022 \\
Yes & 2.60 & \\
Family dietary fruits consumption & & \\
Adequate & 1.0 & $0.57-7.02$ & 0.070 \\
Inadequate & 1.78 & & \\
\hline
\end{tabular}

\section{Discussion}

The prevalence of abdominal obesity of $11.6 \%$ in this study is less than $31.7 \%$ reported among adult patients in Okirika, Rivers State, South-south Nigeria,[2] 21.7\% reported in Abia State, South-east Nigeria,[5] 33.8\% reported in Ogbomoso, South-west Nigeria [22] and 32.0\% reported in Cotonou, Benin Republic. [25] The finding of this study has buttressed the reports that abdominal obesity is an issue of phenomenal medical importance in Nigeria $[1,2,5,22]$ and in other parts of the world such as Cotonou, Benin Republic, [25] United States of America[23], South Korea[24] and Jamaica[38] This study has demonstrated that abdominal obesity is no longer the disease of affluent countries and has corroborated the reports that abdominal obesity exist in Nigeria in variable proportions.[1,2,5,22] The abdominal obese condition could predispose the patients to increase cardio-metabolic morbidity and mortality. $[1,2,38]$ This study therefore creates a pedestal for the patients and their families to understand abdominal obesity as a health risk not an indication of prosperity that can be reduced through lifestyle modifications involving healthy diet, adequate exercise among other diverse interventions. It is therefore pertinent to detect early the development of abdominal obesity in family members particularly among the study population as early intervention may alter morbidity end points. Identification of abdominally obese patients during clinical consultation therefore avails greater opportunities for appropriate health information and health promotion among the family members. Educating these patients and their families on the relevance of waist size determination and its interpretation should be integrated as part of patient and family health education during clinical encounter with abdominally obese patients in the study area.

The family history of obesity was significantly associated with abdominal obesity. Family history of obesity has been reported in previous studies.[2,11,30,31] Accordingly, genetic factors are estimated to explain 30\%$50 \%$ of hereditability of obesity. [39] This study has buttressed the reports of the growing evidence of genetic influences on the development of human obesity.[2,11,37,40] It is therefore likely that genes and other socio-environmental factors interact and potentiate their individual impact on the pathogenetic mechanisms that lead to the emergence of obesity.[41,42,43,44] The finding of this study is very important especially in Nigerian family environment where abdominal obesity is not always perceived as a health risk. [2,11] Although fats act as storage organ for excess calories, its abdominal distribution is however associated with increased risk of cardiovascular diseases. [1,38] Abdominal obesity can therefore have adverse effects on the family health and can trigger other acute and chronic complications of abdominal obesity in family members.[2,11] Screening adult patients with family history of obesity for abdominal obesity needs to be at initial clinical encounter as the development and damage by abdominal obesity start even before the diagnosis is made. The longitudinal and latitudinal care of these patients should be a family care challenge especially in resource-constrained setting where there are limited options for healthy living.

The result of this study has shown that inadequate family dietary fruits consumption was significantly associated with abdominal obesity among the study population. This could be attributed to low priority given to intake of fruits in study area and a reflection of the Nigerian family diet which is predominantly made of carbohydrate.[2,21] More so, the high cost of dietary fruits in the study area is contributory especially in the environment where subsistence and commercial agriculture is at its low ebb with an economy driven by petroleum and petroleum products. Patho-genetically, the mechanism linking dietary factors with cardio-metabolic disorders such as abdominal obesity has been elucidated in medical research.[42,43,45] However abdominal obesity may be considered to be the consequences of chronic ingestion of excess calories amidst other factors.[44] In addition, a positive energy balance between the amounts of energy consumed over the energy expended in day-to-day life contributes to the aetiopathogenesis of abdominal obesity. [6, 8, 44] Furthermore regulation of energy balance is a complex mechanism involving family behavioural, genetic, hormonal, and neural influences [44, 45]. In this regard, beyond individual preventive actions, intervention at level of families could promote healthy eating and prevent future obesity in the family. This study therefore bring to the fore the prospects of controlling obesity through a family friendly and oriented proactive approaches. It emphasis the need for family based intervention strategies in high risk families which should incorporate the need for adequate family dietary fruits consumption habits and other diverse primary prevention interventions.

The most significant predictor variable of abdominal obesity in this study was family history of obesity. This finding is consistent with other reports on the family history of obesity as an important risk factor for development of abdominal obesity.[2,11,29,30,31] This association could be explained partly by the influence of heredity.[29,31,39] This genetic contribution involves 
multiple genes with variable penetrance and expressions. Family studies including twin and adoption studies have established that obesity is heritable, and an individual's risk of obesity is increased when one of his relatives is obese [30]. Apart from genetic predilection, other family behavioural factors such as acquisition of carbohydrate food preference and poor family dietary fruits consumption habits could predispose to emergence of abdominal obesity in the family.[2,37] Although not every patient with family history of obesity are at risk for developing abdominal obesity but their chances are high. Such family members who may not develop abdominal obesity are probably those with low metabolic, behavioural and environmental risk profile. As the prevalence of obesity increases worldwide so will the family history of abdominal obesity increase. With the changing family lifestyle in the study area, the presence of family history of obesity during clinical encounter should provide guide for screening for abdominal obesity and can help tailor health promotion, risk reduction and health maintenance messages to family lifestyle modifications.

\subsection{Implications of the Study}

Abdominal obesity is commonly overlooked as a family health problem whereas its deleterious effects on metabolic homeostasis and cardiovascular health of family members are enormous. One of the pillars identified that reduces obesity-related medical conditions is early recognition and modification of non-constitutional family-behavioural risk factors. However, families with biosocial factors that predispose to abdominal obesity may not recognize the medical implications of abdominal obesity. Inquiring for the family biosocial factors and consideration of its associated medical impact is very important for effective family health services as regards family health promotion and diverse requirements for abdominal obesity. It is envisaged that the mutable family biosocial factors associated with abdominal obesity may change in the future as a result of family health education, and diverse family socio-behavioural changes.

\subsection{Limitations of the Study}

The limitations imposed by the study are recognized by the researchers. First and foremost, the waist circumference was taken at a single point in time and the authors had no information on previous measurements. In addition, the authors had no direct measures of abdominal fat or muscle composition. The researchers also anticipated measurement errors and biases for abdominal adiposity. However, there effects were reduced by using non-stretchable tape and training of the researchers. The training of the research team included standardization of measurement of waist circumference. This was to ensure accuracy and reliability and reduce inter- and intra-observer errors and ensure comparability of measurements.

More so, the limitation of not matching the abdominally obese patients for other socio-demographic characteristics such as occupation, marital status, education and socioeconomic class among others are recognized by the authors This was designed to avoid over-matching on the patients socio-demographic characteristics which might lead to variable degree of systematic error.

Information were collected from the consultand or proband and not from all the family members and so the findings may be subject to information bias. This also made it difficult to study other family variables such as family physical activity among others.

The limitation imposed by the cross sectional study design is recognized. The cross sectional study design didn't allow elucidation of the direct effects of predictor family biosocial variables on abdominal obesity and vice versa. The cross sectional design allows only establishment of an association between dependent and independent variables. Further longitudinal studies to explore the interactions as well as studies to unravel its clinical relevance in the study area are advocated.

Furthermore, the authors didn't measure leptin levels because of absence of facilities for it in the study centre. However, high leptin concentrations are not found in every patient with obesity and not all patients with high leptin levels are obese.[37,40] This study therefore provides useful baseline information on which subsequent interventions in the study area could be based and evaluated.

\subsection{Strengths of the Study}

This is the first study that has highlighted the association between abdominal obesity and family biosocial variables in the study area. The sample size is larger than the minimum estimated sample size and the population of 3012 patients screened for abdominal obesity in a hospital based study is also significant.

\section{Conclusion}

This study has shown that abdominal obesity is associated with family history of obesity and family inadequate dietary fruits consumption. The interventional control programs for abdominal obesity should consider these predictive risk factors alongside the complex of other cardiovascular risk factors. This will invariably improve the quality of care received by these patients and their families who are living in a resource constrained rural setting.

\section{Future Research Direction}

In the study area, further hospital-based and communitybased studies are recommended in order to further explore other family related risk factors of abdominal obesity and its correlates. This will provide valuable clinical and community epidemiological data for collaborative purposes. 


\section{Acknowledgement}

The authors are grateful to Rev. Sister Francisca Eya of St. Vincent de Paul hospital, Amurie-Omanze for permission for the study.

\section{References}

[1] Iloh GUP, Amadi AN, Njoku PU, Ofoedu JN, Awa-Madu J. The magnitude of abdominal adiposity and atherogenic dyslipidaemia among geriatric Nigerians with arterial hypertension in a rural hospital in south-eastern Nigeria. Niger J Clin Pract . 2012; 15: 462-468.

[2] Siminnialayi IM, Emem-Chioma PC, Dapper DV. The prevalence of obesity as indicated by BMI and waist circumference among Nigerian adult attending Family Medicine clinics as outpatients in Rivers state. Niger J Med 2008; 17:340-345.

[3] Okeke EC, Ibeh GN, Ene-Obong HN. Body weight perception among Igbo people in the University of Nigeria, Nsukka. Agro-Science Journal 2006; 5: 17-24.

[4] Abubakar AR, Lander W, Agyemang C, Jones M, Kirk A, Bhopal RS. Prevalence and time trends in obesity among adult West African populations: a meta-analysis. Obesity Reviews 2008; 9: 297-311.

[5] Chukwuonye II, Chuku A, Onyenoro UU, Okpechi IG, Madukwe OO, Umeizudike TI, Ogah OS. Prevalence of abdominal obesity in Abia State, Nigeria: results of a population-based house-to-house survey. Diabetes, Metabolic Syndrome and Obesity: Targets and Therapy 2013; 6: 285-291.

[6] Lean MEJ, Han TS, Seidell JC. Impairment of health and quality of life in people with large waist circumference. Lancet 1998; 351: 853- 856.

[7] Doll S, Paccaud F, Hovet P, Bumier M, Wietlisbach V. Body mass index, abdominal adiposity and blood pressure: consistency of their association across developing and developed countries. Int J Obes 2002; 26: 48-57.

[8] Ziraba AK, Fotso JC, Ochako R. Overweight and obesity in urban Africa: A problem of the rich or the poor? BMC Public Health 2009; 9: 465.

[9] Iloh GUP, Amadi AN, Nwankwo BO, Ugwu VC. Obesity in adult Nigerians: A study of its pattern and common primary co-morbidities in a rural Mission General Hospital in Imo state, south-eastern Nigeria. Niger J Clin Pract 2011; 14: 212-218.

[10] Iloh GUP, Amadi AN, Nwankwo BO. Obesity in adult Nigerians: a study of its prevalence and common primary co-morbidities in a semi-urban Mission General Hospital in South-Eastern Nigeria. Niger J Med 2010; 19: 459-466.

[11] Iloh GUP, Chuku A, Obiegbu NP, Ofoedu JN, Ikwudinma AO. Frequency of cardiovascular risk factors in adult Nigerians with family history of non-communicable cardiovascular disease in a primary care clinic of a tertiary hospital in a resource-constrained environment of Eastern Nigeria. American Journal of Health Research 2013; 1(1): $17-25$.
[12] Kumar S, Gupta A, Jain S. Neck circumference as a predictor of obesity and overweight in rural central India. Int J Med Public Health 2012; 2: 62-66.

[13] Wahrenberg H, Hartel K, Leijonhufvud B. Waist circumference predicts insulin resistance. A retrospective study. BMJ 2005; 330: 1363-1364.

[14] Tokin A. The metabolic syndrome: A growing problem. European Heart Journal Supplement 2004; 6: A32-A42.

[15] Janssen I, Katzmarzyk PT, Ross R. Waist circumference and not body mass index explains obesity-related health risk. Am J Clin Nutrb2004; 79: 379-384.

[16] Fezeu I, Balkau B, Kengne AP, Sobngwi E, Mbanya JC. Metabolic syndrome in a sub-Saharan African setting: central obesity may be the key determinant. Atheroclerosis 2007; 193: 70-76.

[17] Rexrode KM, Burning JE, Manson JE. Abdominal and total adiposity and risk of coronary heart disease in men. Int $\mathrm{J}$ Obes Relat Metab Disord 2001; 25: 1047- 1056.

[18] Rexrode KM, Carey VJ, Hennekens CH. Abdominal adiposity and coronary heart disease in women. JAMA 1998 280: $1843-1848$.

[19] The European Food Information Council. The basics: Obesity and overweight.(Online). 2006. (cited 2008 March); Available from: URL: http://www.eufic.org/article/en/expid/basics-obesityoverweight/.

[20] Adediran O, Akintude AA, Edo AE, Opadijo OG, Araoye AM. Impact of urbanization and gender on frequency of metabolic syndrome among native Abuja settlers in Nigeria. J Cardiovasc Dis Res 2012; 3: 191-196.

[21] Ekpenyong C, Akpan E. Contextual Trend in Preventing Obesity Epidemic in Developing Countries: Role of the Key Players. European Journal of Preventive Medicine. 2013; 1: 20-31.

[22] Amole IO, OlaOlorun AD, Odegah LO, Adesina SA. The prevalence of abdominal obesity and hypertension amongst adults in Ogbomoso, Nigeria. Afr J Prm Health Care Fam Med 2011; 3.188.

[23] Okosun IS, Cooper RS, Prewitt TE, Rotimi CN. The relation of central adiposity to components of the insulin resistance syndrome in a biracial US population sample. Ethn Dis 1999; 9: $218-229$

[24] Park HS, Yun YS, Park JY, Kim YS, Choi JM. Obesity, abdominal obesity, and clustering of cardiovascular risk factors in South Korea. Asia Pac J Clin Nutr 2003;12: 411418.

[25] Sodjinou R, Agueh V, Fayomi B, Delisle H. Obesity and cardio-metabolic risk factors in urban adults of Benin: relationship with socio-economic status, urbanization and lifestyle patterns. BMC Public Health 2008; 8:84.

[26] Oleribe EOO, Alasia DD. Socio-demographic variables and family health: A prospective study of a Katcha in Northcentral Nigeria. Niger J Med 2006; 15: 427-429.

[27] Inem AV, Ayankogbe OO, Obazee M, Ladipo MM, Udonwa NE, Odusote K. Conceptual and contextual paradigm of the family as a unit of care. Niger Med Pract 2004; 45: 9-13. 
[28] Iloh GUP, Ikwudinma AO, Obiegbu NP. Obesity and its cardio-metabolic co-morbidities among adult Nigerians in a Primary Care Clinic of a tertiary hospital in South-eastern Nigeria. J Fam Med Primary Care 2013; 2: 20-26.

[29] Marti A, Moreno-Aliaga MJ, Hebebrand and Martinez JA. Genes, lifestyle and obesity. Int $\mathrm{J}$ Obes Relat Metab Disord.2004, 28 Suppl 3: S29-S36.

[30] Yang W, Kelly T, He J. Genetic epidemiology of obesity. Epidemiol Rev. 2007; 29:49-61.

[31] Froguel P, Boutin P. Genetics of pathways regulating body weight in the development of obesity in humans. Exp Biol Med (Maywood). 2001; 226:991-996.

[32] Ibrahim T. Sample size determination. In: Research Methodology and Dissertation writing for Health and Allied Health Professionals. Abuja, Nigeria Cress Global Link Limited; 2009: p.70-75.

[33] Iloh GUP, Ikwudinma AO. Abdominal obesity in adult Nigerian Africans: prevalence and co-occurrence with cardio-metabolic risk factors in a resource poor setting of a rural hospital in Eastern Nigeria. American Journal of Health Research 2013; 1(3): 73-80

[34] Chobanian AV, Bakris GL, Black HR, Cushman WC, Green LA, Izzo JL et al. The seventh report of the Joint National Committee on Prevention, Detection, Evaluation and Treatment of high blood pressure: The JNC VII report. JAMA 2003; 289: 2560- 2572.

[35] American Diabetes Association: Diagnosis criteria for diabetes mellitus. Diagnosis and classification of diabetes mellitus. Diabetes Care 2010; 33(Suppl 1): S62-S69.
[36] WHO. Survey of the STEPwise approach for the survellaince of risk factors for non-communicable diseases, Brazzaville, WHO, Region office for Africa, 2007.

[37] Oyekan AO. Genetics of food intake, body weight and obesity-role of leptin. Niger Med Pract 2005; 47:108-112

[38] Okosun IS, Cooper RS, Rotimi CN, Osotimehin B, Forrester T. Association of waist circumference with risk of hypertension and type 2 diabetes in Nigerians, Jamaicans and African-Americans. Diabetes Care 1998; 21: 1836-1842.

[39] Finer N. Obesity. Clinical Medicine 2003; 3: 23-27.

[40] Ruhl CE. Leptin concentrations in the United States: relations with demographic and anthropometric measures. Am J Clin Nutr 2001; 74: 295.

[41] Ratimouni H. Leptin and the cardiovascular system. Res Horm Res 2004; 79: 224-244.

[42] Willet WC. Diet and health: what should we eat? Science 1994; 532-537.

[43] Rimm EB, Ascherio A, Giovannucci E, Speigelman D, Stampfer MJ, Willet WC. Vegatables, fruits and cereal fibre intake and risk of coronary heart disease among men. JAMA 1996; 275: 447-451.

[44] Weber J. Energy balance in obesity. Proc Nutr Soc. 2003; $62: 539-543$

[45] Ramos DC, Mehta R, De La Luz Castro J, Limones RC, Rubi EG, Aguilar-Salinas CA. Awareness of Abdominal Adiposity as a cardiometabolic Risk Factor (The 5A Study): Mexico. Diabetes Meta Syndr Obes 2011; 4: 107-117. 